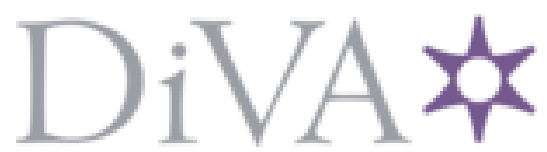

http://www.diva-portal.org

This is the published version of a paper published in Proceedings of the National Academy of Sciences of the United States of America.

Citation for the original published paper (version of record):

Hintz, W D., Arnott, S E., Symons, C C., Greco, D A., McClymont, A. et al. (2022)

Current water quality guidelines across North America and Europe do not protect lakes from salinization

Proceedings of the National Academy of Sciences of the United States of America, 119(9): e2115033119

https://doi.org/10.1073/pnas.2115033119

Access to the published version may require subscription.

N.B. When citing this work, cite the original published paper.

Permanent link to this version:

http://urn.kb.se/resolve?urn=urn:nbn:se:lnu:diva-110590 


\title{
Current water quality guidelines across North America and Europe do not protect lakes from salinization
}

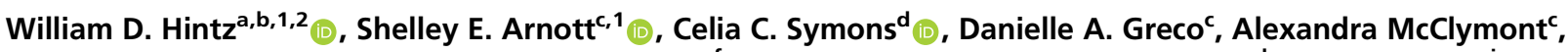 \\ Jennifer A. Brentrup ${ }^{e}{ }^{\circ}$, Miguel Cañedo-Argüelles ${ }^{f}$, Alison M. Derry ${ }^{9}{ }^{\circ}$, Amy L. Downing ${ }^{h}$, Derek K. Gray',

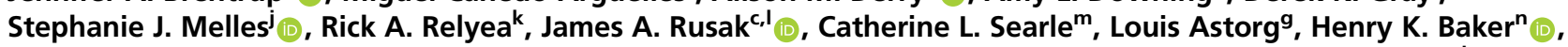

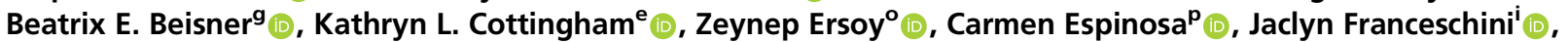

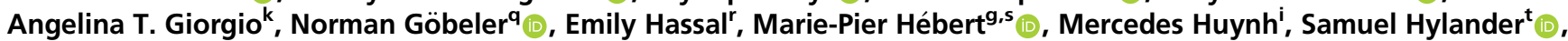

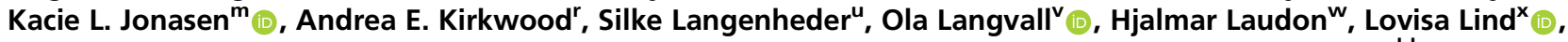

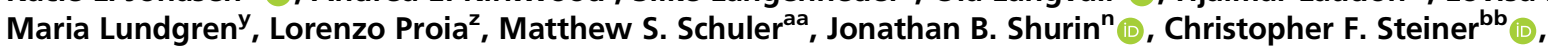

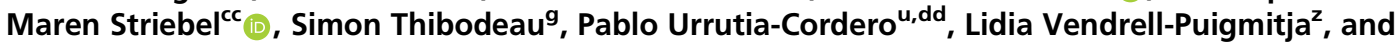 \\ Gesa A. Weyhenmeyer" ${ }^{\mathrm{u}}$ (1)
}

Edited by Andrea Rinaldo, Laboratory of Ecohydrology, School of Architecture, Civil and Environmental Engineering, Ecole Polytechnique Federale de Lausanne, Lausanne, Switzerland; received August 16, 2021; accepted January 10, 2022

Human-induced salinization caused by the use of road deicing salts, agricultural practices, mining operations, and climate change is a major threat to the biodiversity and functioning of freshwater ecosystems. Yet, it is unclear if freshwater ecosystems are protected from salinization by current water quality guidelines. Leveraging an experimental network of land-based and in-lake mesocosms across North America and Europe, we tested how salinization-indicated as elevated chloride $\left(\mathrm{Cl}^{-}\right)$concentration-will affect lake food webs and if two of the lowest $\mathrm{Cl}^{-}$thresholds found globally are sufficient to protect these food webs. Our results indicated that salinization will cause substantial zooplankton mortality at the lowest $\mathrm{Cl}^{-}$thresholds established in Canada $\left(120 \mathrm{mg} \mathrm{Cl}^{-} / \mathrm{L}\right)$ and the United States $\left(230 \mathrm{mg} \mathrm{Cl}^{-} / \mathrm{L}\right)$ and throughout Europe where $\mathrm{Cl}^{-}$thresholds are generally higher. For instance, at $73 \%$ of our study sites, $\mathrm{Cl}^{-}$concentrations that caused $a \geq 50 \%$ reduction in cladoceran abundance were at or below $\mathrm{Cl}^{-}$ thresholds in Canada, in the United States, and throughout Europe. Similar trends occurred for copepod and rotifer zooplankton. The loss of zooplankton triggered a cascading effect causing an increase in phytoplankton biomass at $\mathbf{4 7 \%}$ of study sites. Such changes in lake food webs could alter nutrient cycling and water clarity and trigger declines in fish production. Current $\mathrm{Cl}^{-}$thresholds across North America and Europe clearly do not adequately protect lake food webs. Water quality guidelines should be developed where they do not exist, and there is an urgent need to reassess existing guidelines to protect lake ecosystems from human-induced salinization

biodiversity | climate change | environmental policy | land use water quality

$\mathbf{H}$ uman-induced salinization caused by the application of road deicing salts, agricultural practices, resource mining, and climate change has triggered a global increase in the salinity of fresh waters $(1,2)$. For instance, in regions that experience cold winters, millions of metric tons of inorganic road deicing salts are applied annually to protect the traveling public by improving road safety. After deicing salts dissolve in rainwater and snowmelt, they wash into adjacent surface and ground waters triggering a substantial increase in salinity (3-5) - in some instances, a salinity level that is $25 \%$ the concentration of seawater (6). The application of fertilizers such as potash (potassium chloride $[\mathrm{KCl}]$ ) and evapotranspiration during intensive irrigation in agricultural operations concentrate salts on the surface of agricultural soils, which are then transported into nearby fresh waters during precipitation events increasing freshwater salinity (7). Coastal freshwater ecosystems are also under threat. Seawater intrusion due to sea level rise caused by climate change is triggering salinization of coastal freshwater ecosystems (8). Most freshwater ecosystems, particularly inland fresh waters, have had very low salinity throughout recent geological history. Thus, it is critical we understand how freshwater organisms will respond to such widespread salinization, which is predicted to trigger a loss of ecosystem services such as drinking water quality, recreational opportunity, property

\section{Significance}

The salinity of freshwater ecosystems is increasing worldwide. Given that most freshwater organisms have no recent evolutionary history with high salinity, we expect them to have a low tolerance to elevated salinity caused by road deicing salts, agricultural practices, mining operations, and climate change. Leveraging the results from a network of experiments conducted across North America and Europe, we showed that salt pollution triggers a massive loss of important zooplankton taxa, which led to increased phytoplankton biomass at many study sites. We conclude that current water quality guidelines established by governments in North America and Europe do not adequately protect lake food webs, indicating an immediate need to establish guidelines where they do not exist and to reassess existing guidelines.

Author contributions: W.D.H., S.E.A., D.A.G., A.M., M.C.-A., A.M.D., D.K.G., S.J.M., R.A.R., J.A.R., C.L.S., K.L.C., Z.E., C.E., N.G., M.-P.H., A.E.K., S.L., L.L., L.P., M.S.S., M.S., P.U.-C., L.V.-P., and G.A.W. designed research; W.D.H., S.E.A., C.C.S., D.A.G., A.M., J.A.B., M.C.-A., A.M.D., A.L.D., D.K.G., S.J.M., R.A.R., J.A.R., C.L.S., L.A., H.K.B., K.L.C., Z.E., C.E., J.F., A.T.G., N.G., E.H., M.-P.H., M.H., K.L.J., A.E.K., S.L., O.L., L.L., M.L., L.P., M.S.S., J.B.S., C.F.S., M.S., S.T., P.U.-C., L.V.-P., and G.A.W. performed research; W.D.H., S.E.A., C.C.S., D.A.G., A.M., J.A.B., M.C.-A., A.M.D., A.L.D., D.K.G., S.J.M., R.A.R., J.A.R., C.L.S., L.A., J.F., M.-P.H., and G.A.W. analyzed data; and W.D.H., S.E.A., C.C.S., D.A.G., A.M., J.A.B., M.C.-A., A.M.D., A.L.D., D.K.G., S.J.M., R.A.R., J.A.R., C.L.S., H.K.B., B.E.B., K.L.C., Z.E., C.E., J.F., A.T.G., N.G., M.-P.H., S.H., K.L.J., A.E.K., S.L., O.L., H.L., L.L., M.L., L.P., M.S.S., J.B.S., C.F.S., M.S., S.T., P.U.-C., and G.A.W. wrote the paper.

The authors declare no competing interest.

This article is a PNAS Direct Submission.

This article is distributed under Creative Commons Attribution-NonCommercialNoDerivatives License 4.0 (CC BY-NC-ND).

${ }^{1}$ W.D.H. and S.E.A. contributed equally to this work.

${ }^{2}$ To whom correspondence may be addressed. Email: hintzwd@gmail.com.

This article contains supporting information online at http://www.pnas.org/lookup/ suppl/doi:10.1073/pnas.2115033119/-/DCSupplemental.

Published February 22, 2022. 
values, and fisheries (1). Moreover, increased water demands and climate change are expected to intensify freshwater salinization worldwide $(9,10)$.

In lake ecosystems, salinization can affect freshwater organisms at multiple trophic levels (11). Zooplankton are ubiquitous and critical to lake food webs because they transfer energy from primary producers to higher-level consumers. This zooplankton-phytoplankton pathway supports freshwater fisheries, influences nutrient cycling, and has a strong effect on water quality and clarity $(12,13)$. A change in this energy pathway in lake food webs could trigger a significant loss of resources that lakes provide $(14,15)$. For instance, a reduction in the abundance and diversity of zooplankton reduced fish growth and recruitment in Lake Michigan in the United States (16). To date, our understanding of how salinization affects the zooplankton-phytoplankton pathway is limited, restricting our ability to generalize the impacts of salinization on lake food webs and develop policies to protect lakes.

One of the chemical signals of salinization in lakes is an elevated chloride $\left(\mathrm{Cl}^{-}\right)$concentration. For example, $\mathrm{Cl}^{-}$is a good measure of road salt pollution because it acts as a conservative tracer (i.e., is not biologically transformed) (17) and is the anion of the most commonly used deicing salts: sodium chloride $(\mathrm{NaCl})$, calcium chloride $\left(\mathrm{CaCl}_{2}\right)$, and magnesium chloride $\left(\mathrm{MgCl}_{2}\right)$. Similarly, $\mathrm{Cl}^{-}$is also a good tracer for identifying other sources of salt pollution from agriculture fertilizers [e.g., $\mathrm{KCl}$ (18)] or seawater intrusion (19). Thus, governments in many countries such as the United States, Canada, Germany, and Sweden use $\mathrm{Cl}^{-}$concentration to set thresholds to protect freshwater organisms or drinking water sources. Currently, the lowest thresholds to protect freshwater organisms are $230 \mathrm{mg}$ $\mathrm{Cl}^{-} / \mathrm{L}$ in the United States and $120 \mathrm{mg} \mathrm{Cl}^{-} / \mathrm{L}$ in Canada (20, 21). In Europe, chloride standards for freshwater ecosystems are largely absent (22), but there are some exceptions. In Germany, $\mathrm{Cl}^{-}$concentrations of 50 to $\leq 200 \mathrm{mg} \mathrm{Cl}^{-} / \mathrm{L}$ are classified as slightly polluted by salts, and concentrations of 200 to 400 $\mathrm{mg} \mathrm{Cl}-/ \mathrm{L}$ are classified as moderately polluted by salts, while the drinking water guideline is $250 \mathrm{mg} \mathrm{Cl}^{-} / \mathrm{L}$ across much of Europe [e.g., Sweden (23)].

At present, we do not know if $\mathrm{Cl}^{-}$thresholds will protect lake food webs in countries where $\mathrm{Cl}^{-}$thresholds exist. Some studies indicate dramatic negative effects on zooplankton near or just above the US and Canadian $\mathrm{Cl}^{-}$thresholds of 230 and $120 \mathrm{mg} \mathrm{Cl}^{-} / \mathrm{L}$, respectively (24-26). Others found toxic effects only at extremely high $\mathrm{Cl}^{-}$concentrations (27-29). One recent study suggests population declines in freshwater zooplankton

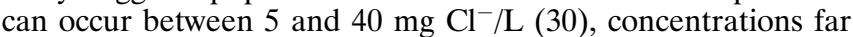
below the thresholds set by the United States and Canada and throughout Europe. The reasons for the variability among studies exploring the effects of salinization on zooplankton remain unclear. Lakes have diverse water chemistry, trophic state, and food web structure-properties which can affect the response of freshwater organisms to rising salinity $(15,31,32)$. For instance, calcium concentration can affect the toxicity of $\mathrm{Cl}^{-}$on freshwater zooplankton $(32,33)$, and lake ecosystems worldwide vary substantially in calcium concentration (34). Thus, differences among watersheds including water chemistry, historical exposure to salinity, different methodologies, community structure, and distinct genetic strains might explain variability among published studies (35). Further, nearly all previous studies have been single-lake studies or laboratory experiments with ideal conditions, further complicating our ability to estimate the overall threat that increased salinity poses to lake food webs and set sound regulatory thresholds or change existing ones.

To accurately generalize the effects of salinization on lake food webs, we need to compare responses using standardized methods while incorporating local differences in species composition and environmental conditions of lake water. Because experimental networks that replicate and standardize experiments across space and time can overcome this limitation [e.g., Nutrient Network (36), Zostera Experimental Network (37), and the Swedish Infrastructure for Ecosystem Science (SITES) AquaNet (38)], we established an experimental network of 16 sites across North America and Europe to identify responses of lake food webs to salinization triggered by $\mathrm{NaCl}$, one of the most common salt types leading to the salinization of freshwater lakes (e.g., from road salt use). Further, using zooplankton communities from natural habitats has an advantage over short-duration (e.g., 48-h toxicity tests), single-species laboratory studies because such an approach encompasses a greater diversity of species and naturally occurring predator-prey and competitive interactions within the zooplankton community. We focused on determining if current $\mathrm{Cl}^{-}$-based water quality guidelines protect lake food webs in regions with different geology, water chemistry, land use, and species pools. We predicted a disruption in the zooplankton-phytoplankton energy pathway would occur at higher salinities and would be manifested by reduced abundance of major zooplankton taxa, resulting in a concomitant increase in phytoplankton when compared with unsalinized control conditions. We also expected that local species pools would vary in their response to elevated salinity and that site-level water chemistry and environmental conditions would explain variation in the responses across experimental sites. Specifically, we predicted that higher concentrations of three essential nutrients (calcium, nitrogen, and phosphorus) and food resources (phytoplankton) among the study sites would reduce the impacts of elevated salinity on zooplankton.

\section{Results}

Our global generalized additive model (GAM) indicated that a site-specific model explained more variation in the response for each zooplankton taxa among our study sites (SI Appendix, Appendix 4, Table 4.6). Thus, we proceeded with site-specific GAMs to evaluate the zooplankton responses to our $\mathrm{Cl}^{-}$concentration gradient (SI Appendix, Appendix 4, Table 4.7).

Across study sites, the response of all zooplankton taxa to the $\mathrm{Cl}^{-}$concentration gradient was generally nonlinear and negative (e.g., Fig. 1 and SI Appendix, Appendix 4, Figs. 4.1-4.4). The site-specific GAMs allowed us to estimate the lethal concentration values that caused a $50 \%$ reduction in abundance $\left(\mathrm{LC}_{50}\right) \pm$ 95\% confidence intervals (CIs) for most zooplankton taxa among the study sites. Many of these $\mathrm{LC}_{50}$ values $\pm 95 \% \mathrm{CIs}$ overlapped or were below the lowest two $\mathrm{Cl}^{-}$thresholds established by the Canadian and US governments to protect aquatic life in these countries. We also found that the GAMs predicted significant declines in zooplankton abundance among all taxa and at the vast majority of our study sites at the Canadian threshold of $120 \mathrm{mg} \mathrm{Cl}^{-} / \mathrm{L}$ and US threshold of $230 \mathrm{mg} \mathrm{Cl}^{-} / \mathrm{L}$. The environmental variables we measured generally did not explain the negative response of zooplankton to our $\mathrm{Cl}^{-}$concentration gradient. The loss of zooplankton grazers led to a higher biomass of phytoplankton at $47 \%$ of our study sites (e.g., Fig. 1).

LC 50 Values Relative to $\mathbf{C l}^{-}$Thresholds. We found considerable variability among the predicted $\mathrm{LC}_{50}$ values across the study sites. Based on the $\mathrm{LC}_{50}$ values, calanoid copepod, cladoceran, and rotifer zooplankton were the most susceptible to our environmentally relevant $\mathrm{Cl}^{-}$concentrations. Cyclopoid copepod zooplankton had the lowest number of sites $(33 \%)$ where $\mathrm{LC}_{50}$ values overlapped with or were below the Canadian and US $\mathrm{Cl}^{-}$thresholds.

We were able to estimate $\mathrm{LC}_{50}$ values with $95 \%$ CIs for cladoceran zooplankton at all study sites that contained cladocerans ( 15 of 15 ; Fig. $2 A$ ). These values indicated a substantial loss of cladoceran zooplankton occurred. The $\mathrm{LC}_{50}$ values $\pm 95 \%$ CIs at $73 \%(n=11)$ of our sites overlapped with or were below 


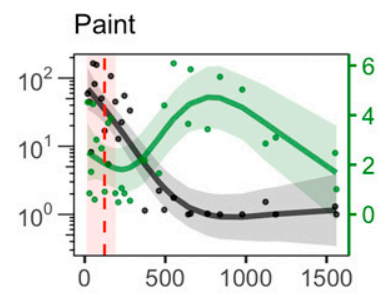

Purdue

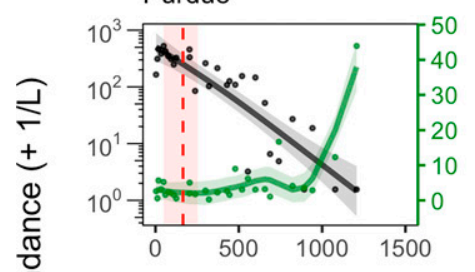

Opeongo

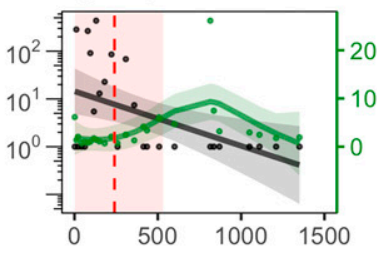

Feresjon

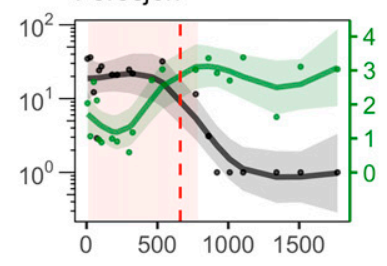

Long

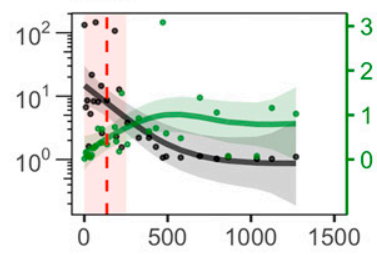

Stortjarn

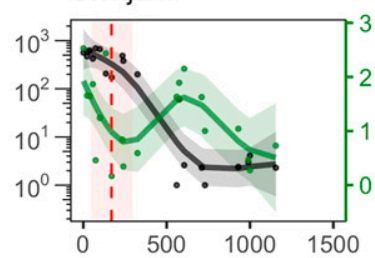

Kraus

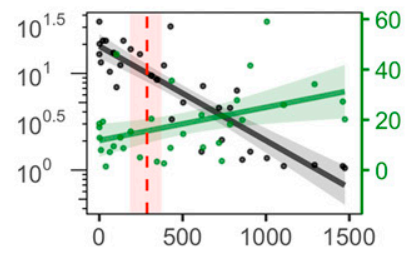

Erken

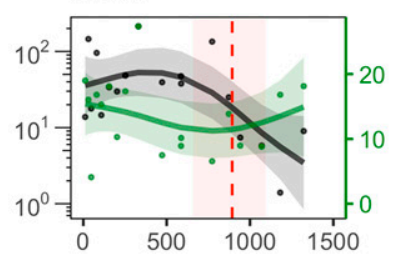

Dartmouth

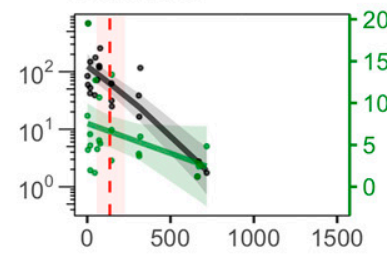

Croche

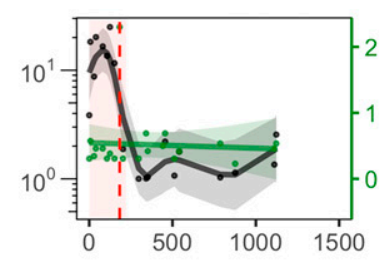

Hertel

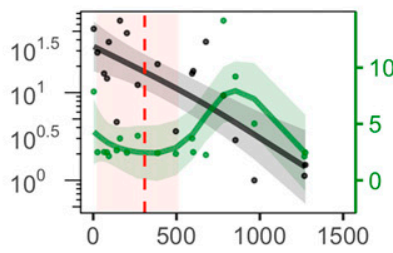

Convict

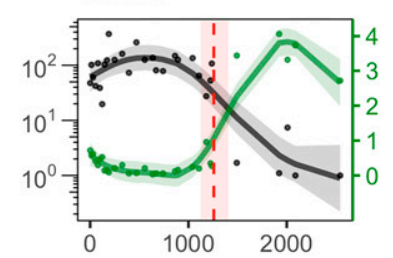

Sturgeon

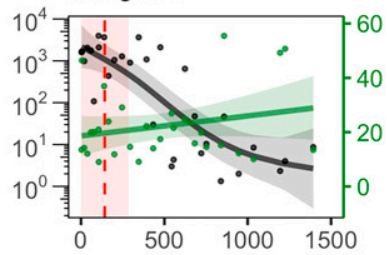

George

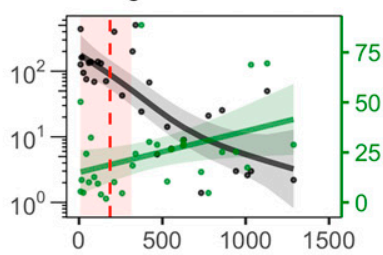

KBS Reservoir

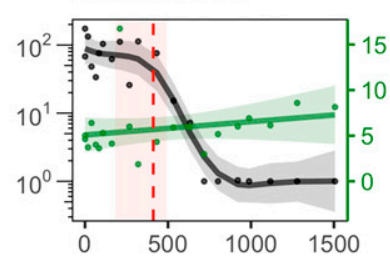

Tavernoles

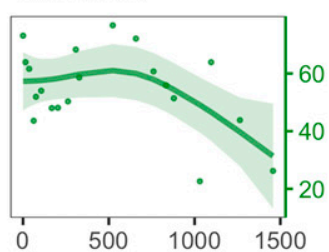

Fig. 1. GAMs and $95 \% \mathrm{Cls}$ (shaded regions) for cladoceran zooplankton abundance (black line) and chlorophyll a concentration (i.e., phytoplankton biomass; green line) among 16 experimental sites throughout North America and Europe. Cladocerans are featured as they are generally regarded as the largest, highest-biomass filter-feeding zooplankton grazers in our study systems. The vertical red dashed line indicates the lethal concentration value $\left(\mathrm{LC}_{50}\right)$ representing the $\mathrm{Cl}^{-}$concentration at which there was a $50 \%$ reduction in abundance of each zooplankton taxa for each site with the associated 95\% Cls (red shaded region around the dashed line). Graphs for calanoid and cyclopoid copepods and rotifers are shown in SI Appendix, Appendix 4, Figs. 4.2-4.4. No cladocerans were found at the Tavernoles study site in Spain.

the Canadian threshold of $120 \mathrm{mg} \mathrm{Cl}^{-} / \mathrm{L}$, and $\mathrm{LC}_{50}$ values $\pm 95 \%$ CIs overlapped with or were below the US threshold of $230 \mathrm{mg} \mathrm{Cl}^{-} / \mathrm{L}$ at $86 \%$ of our sites. At two sites (Erken and Convict), the $\mathrm{LC}_{50}$ values were above the $\mathrm{Cl}^{-}$thresholds. One site did not contain any cladocerans.

For calanoid copepod zooplankton, we were able to estimate $\mathrm{LC}_{50}$ values with $95 \%$ CIs at 11 of 12 study sites that contained calanoids (Fig. $2 B$ ). Four sites did not contain any calanoid zooplankton. In general, there was a rapid decline in calanoid abundance as $\mathrm{Cl}^{-}$concentration increased (SI Appendix, Appendix 4, Fig. 4.2), which did not allow us to estimate an $\mathrm{LC}_{50}$ value for one site (Stortjärn). The calanoid $\mathrm{LC}_{50}$ values $\pm 95 \%$ CIs overlapped with or were below both the Canadian threshold of $120 \mathrm{mg} \mathrm{Cl}^{-} / \mathrm{L}$ and US threshold of $230 \mathrm{mg} \mathrm{Cl}^{-} / \mathrm{L}$ at $90 \%$ of study sites. At one site (Dartmouth), the $\mathrm{LC}_{50}$ value was above both $\mathrm{Cl}^{-}$thresholds.

We were able to estimate $\mathrm{LC}_{50}$ values with $95 \%$ CIs for cyclopoid copepod zooplankton at 15 of the 16 study sites (Fig. $2 C$ ). At one site (Purdue), cyclopoid zooplankton abundance did not increase or decrease along the $\mathrm{Cl}^{-}$concentration gradient (SI Appendix, Appendix 4, Fig. 4.3), so no $\mathrm{LC}_{50}$ was estimated. For $33 \%(n=5)$ of the remaining 15 study sites, the $\mathrm{LC}_{50}$ values $\pm 95 \%$ CIs overlapped with or were below the
Canadian threshold of $120 \mathrm{mg} \mathrm{Cl}^{-} / \mathrm{L}$. The $\mathrm{LC}_{50}$ values $\pm 95 \%$ CIs overlapped with or were below the US threshold of $230 \mathrm{mg}$ $\mathrm{Cl}^{-} / \mathrm{L}$ at $60 \%(n=9)$ of the 15 sites. At $40 \%(n=6)$ of sites with estimable $\mathrm{LC}_{50}$ values for cyclopoids, the values were above the Canadian and US thresholds.

For rotifer zooplankton, we were able to estimate $\mathrm{LC}_{50}$ values with $95 \%$ CIs at 11 of the 16 study sites (Fig. 2D). For these sites, $73 \%(n=8)$ of them had LC $_{50}$ values $\pm 95 \%$ CIs that overlapped with or were below the Canadian threshold of $120 \mathrm{mg} \mathrm{Cl}^{-} / \mathrm{L}$, and $82 \%(n=9)$ of them overlapped with or were below the US threshold of $230 \mathrm{mg} \mathrm{Cl}^{-} / \mathrm{L}$. At multiple sites, rotifer abundance fluctuated substantially or increased along the $\mathrm{Cl}^{-}$concentration gradient (SI Appendix, Appendix 4, Fig. 4.4), which did not allow us to estimate an $\mathrm{LC}_{50}$ value at four sites (Dartmouth, Kraus, Kellogg Biological Station [KBS] Reservoir, and Convict). At two study sites (George and Tavernoles), the estimated $\mathrm{LC}_{50}$ values were above the Canadian and $\mathrm{US} \mathrm{Cl}^{-}$thresholds.

Relationships between Local Environmental Conditions, the $\mathbf{L C}_{50}$ for Zooplankton Taxa, and Community Composition. Local environmental conditions did not affect the predicted $\mathrm{LC}_{50}$ values for three of the four zooplankton taxa (cladocerans, cyclopoids, or 

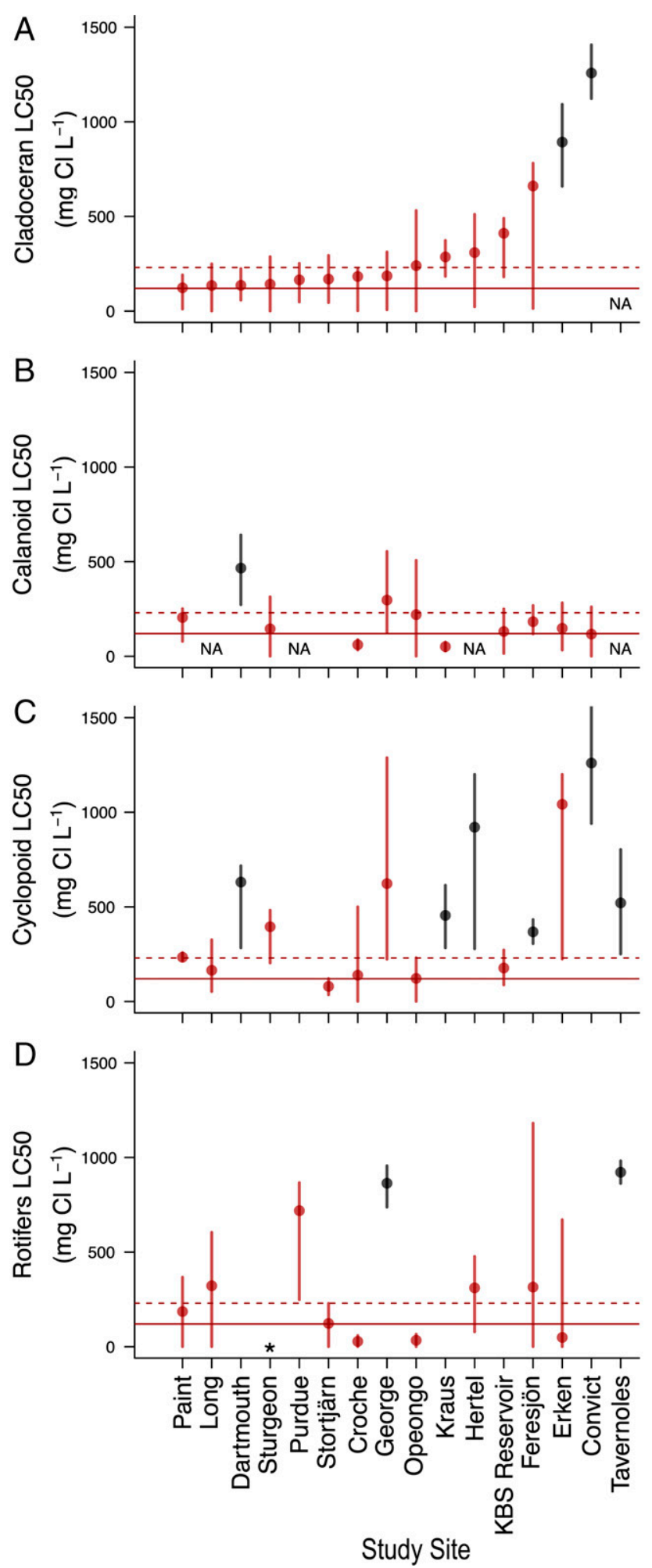

Fig. 2. $\mathrm{LC}_{50}$ representing the $\mathrm{Cl}^{-}$concentration at which there was a $50 \%$ reduction in abundance of each zooplankton taxa across experimental sites $(A)$ Cladocerans, $(B)$ Calanoids, $(C)$ Cyclopoids, and $(D)$ Rotifers. The horizontal red lines highlight the lowest global $\mathrm{Cl}^{-}$thresholds for protecting aquatic life, which are set by governments in Canada (solid line, 120 $\mathrm{mg} \mathrm{Cl}{ }^{-} / \mathrm{L}$ ) and the United States (dashed line, $230 \mathrm{mg} \mathrm{Cl}^{-} / \mathrm{L}$ ). Vertical bars represent $95 \% \mathrm{Cls}$. Points and $95 \% \mathrm{Cls}$ are red when they overlap with or were below the US threshold of $230 \mathrm{mg} \mathrm{Cl}^{-} / \mathrm{L}$. When a zooplankton taxon is not found in the mesocosm experiment, it is noted as "NA." One experiment did not count rotifers, denoted with an asterisk. LC $_{50}$ values were calanoids) or community composition, but environmental conditions (principal component [PC] 1 and PC2 based on water chemistry and chlorophyll $a$ ) explained variation in $\mathrm{LC}_{50}$ values for rotifers. The first axis of our principal component analysis (PCA) explained $51.5 \%$ of the variation and was primarily related to nutrient concentrations (total nitrogen [TN] and total phosphorus [TP]) and chlorophyll $a$, whereas the second axis was related to ion concentrations $\left(\mathrm{Ca}^{2+}\right.$ and $\left.\mathrm{Cl}^{-}\right)$and explained $21.9 \%$ of the variation (SI Appendix, Appendix 6, Fig. 6.1). There was a positive relationship between water chemistry and rotifer $\mathrm{LC}_{50}$ values, driven by nutrients and ion concentrations (rotifer $\mathrm{LC}_{50} \approx \mathrm{PC} 1+\mathrm{PC} 2 ; F_{2,7}=11.95, P=0.006,{ }_{\text {adj }} R^{2}=$ 0.71 ), with rotifers being less sensitive at higher nutrient and ion concentrations. Community composition, represented by the first two axes of the PCA for each taxonomic group, did not explain any of the variation in $\mathrm{LC}_{50}$ values within any of the zooplankton taxonomic groups.

Magnitude of Changes in Zooplankton Abundance Relative to $\mathrm{Cl}^{-}$ Thresholds. We estimated the change in abundance at the Canadian (120 $\left.\mathrm{mg} \mathrm{Cl}^{-} / \mathrm{L}\right)$ and US (230 $\left.\mathrm{mg} \mathrm{Cl}^{-} / \mathrm{L}\right)$ thresholds using GAM models by comparing the predicted abundances at each threshold to the predicted abundance in control conditions. For each zooplankton group, responses in abundance to the $\mathrm{Cl}^{-}$ concentration gradient were generally nonlinear and negative. Substantial declines were observed at many study sites, and at a few sites, some zooplankton taxa disappeared altogether.

Cladoceran zooplankton were detected at 15 of our study sites and were predicted to decline at $80 \%(n=12)$ of those 15 study sites. The abundance of cladocerans declined by 17 to $49 \%$ at the Canadian threshold of $120 \mathrm{mg} \mathrm{Cl}^{-} / \mathrm{L}$ compared to the sitespecific control concentrations (Fig. 3). Cladoceran abundance declined by 22 to $83 \%$ among the same sites at the US threshold of $230 \mathrm{mg} \mathrm{Cl}^{-} / \mathrm{L}$. At three sites (Feresjön, Erken, and Convict), there was a positive effect of elevated $\mathrm{Cl}^{-}$concentration on cladoceran abundance at the Canadian and US thresholds. However, at one of those sites (Feresjön), the error bars overlapped with the no-change threshold (dashed line in Fig. 3).

Calanoid copepod zooplankton were detected at 12 of our study sites and were predicted to decline at $92 \%(n=11)$ of those sites. At the Canadian threshold, calanoid abundance declined by 6 to $83 \%$ compared to the control concentrations among 11 study sites (Fig. 3). Among the same sites and at the US chronic threshold, calanoid abundance declined by 15 to $96 \%$ compared to control $\mathrm{Cl}^{-}$concentrations. At one study site (Stortjärn), there was a predicted increase in calanoid abundance (6 to $11 \%$ ), but the error bars overlapped with the no-change threshold (dashed line in Fig. 3).

Cyclopoid copepod zooplankton were detected at all our study sites. Cyclopoid abundance was predicted to decline at $88 \%(n=14)$ of the sites (Fig. 3). At the Canadian threshold, cyclopoid abundance declined by 7 to $69 \%$ among 14 sites compared to the control conditions. Among the same sites and at the US threshold, calanoid abundance declined by 13 to $96 \%$ compared to control $\mathrm{Cl}^{-}$concentrations. At two sites (Feresjön and Convict), $\mathrm{Cl}^{-}$concentrations at both thresholds were predicted to have a positive effect on cyclopoid abundance.

Rotifer zooplankton were detected at all our study sites but were not counted at one site. Rotifer abundance was predicted to decline at $73 \%(n=11)$ of the sites (Fig. 3). At the Canadian $\mathrm{Cl}^{-}$ threshold, rotifer abundance declined by 5 to $97 \%$ compared to the control concentrations among 11 sites. Among the same sites

not estimable when model fits were unreliable due to a rapid decline in abundance to zero along the $\mathrm{Cl}^{-}$gradient, there was no change, or an increase in abundance with $\mathrm{Cl}^{-}$(for missing values, see Materials and Methods). 


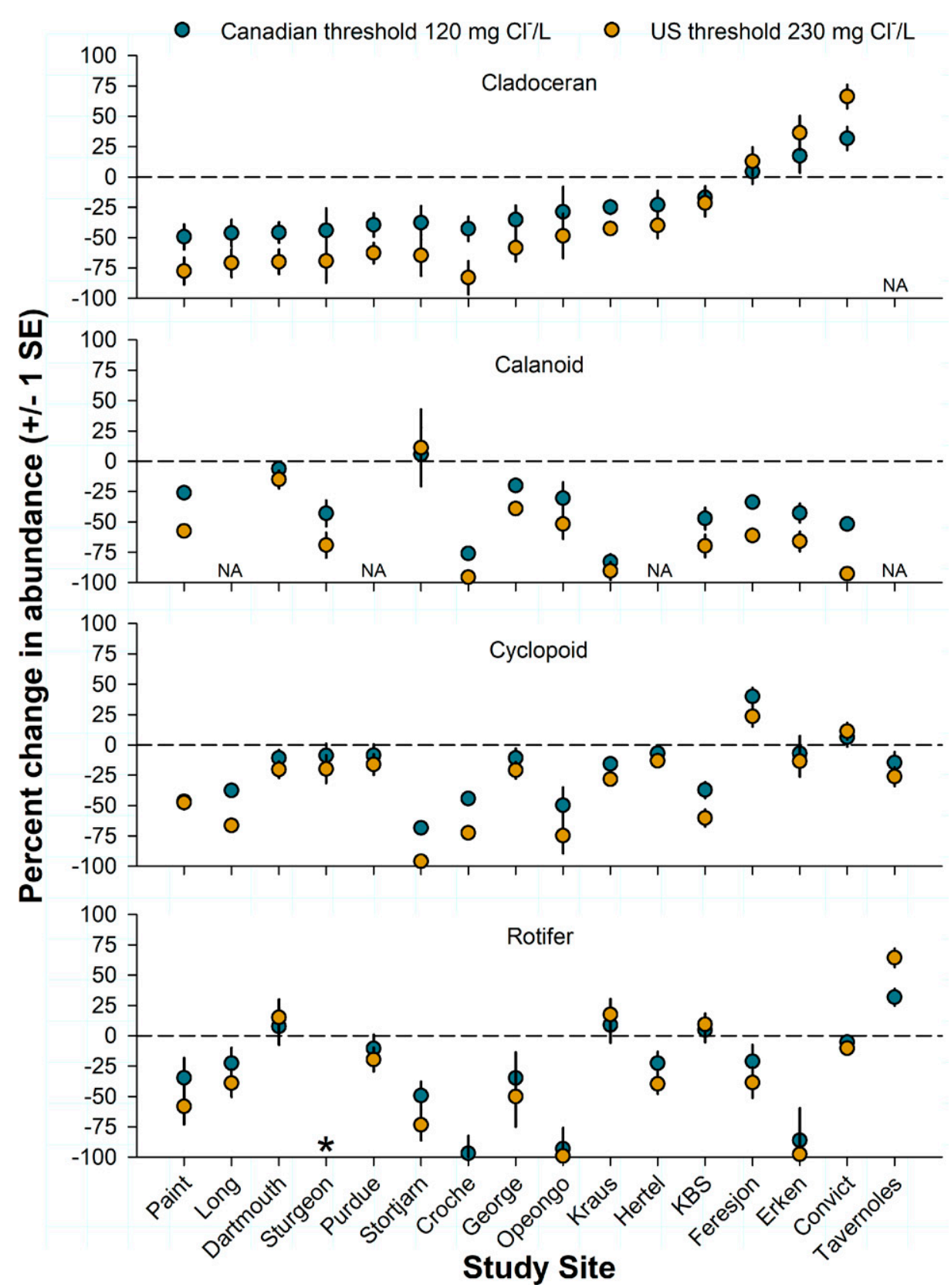

Fig. 3. Mean ( $\pm 1 \mathrm{SE}$ ) of the estimated percent change in zooplankton abundances for each taxa at the Canadian ( $\left.120 \mathrm{mg} \mathrm{Cl}^{-} / \mathrm{L}\right)$ and $\mathrm{US}\left(230 \mathrm{mg} \mathrm{Cl}^{-} / \mathrm{L}\right.$ ) chronic threshold for $\mathrm{Cl}^{-}$. Percent changes were estimated using GAM models to compare the predicted abundances at each threshold to the predicted abundance in control conditions.

and at the US chronic threshold, rotifer abundance declined by 10 to $100 \%$ compared to control $\mathrm{Cl}^{-}$conditions. At four sites (KBS Reservoir, Dartmouth, Kraus, and Tavernoles), $\mathrm{Cl}^{-}$concentrations at both thresholds were predicted to have a positive effect on rotifer abundance, although the error surrounding the predicted decline at three sites (KBS Reservoir, Dartmouth, and Kraus) overlapped with the no-change threshold (dashed line in Fig. 3).

Cascading Effects. We used the correlation between cladoceran abundance and phytoplankton biomass (i.e., chlorophyll $a$ ) to evaluate whether a cascading effect occurred at the 15 study sites where cladocerans were found (Fig. 1). At $47 \%(n=7)$ of the 15 sites, there was a negative correlation between cladoceran abundance and phytoplankton biomass (Table 1). We did not detect a correlation between cladoceran abundance and phytoplankton biomass at seven sites. At one site (Dartmouth), there was a positive relationship between cladoceran abundance and chlorophyll $a$.

\section{Discussion}

Our results indicate that lake food webs change in response to freshwater salinization. Our experimental $\mathrm{Cl}^{-}$concentrations commonly found in natural systems throughout the world led to large reductions in the abundance of major zooplankton taxa and increases in phytoplankton biomass. For $73 \%$ of our study sites, a $50 \%$ decline in the abundance of the four major zooplankton taxa could occur in $\mathrm{Cl}^{-}$concentrations at or below thresholds established by governments in North America and Europe. The loss of zooplankton led to an increase in phytoplankton biomass at almost half of our study sites. Our results 
Table 1. Correlations between $\log _{10}(x+1)$-transformed cladoceran abundance and $\log _{10}$-transformed chlorophyll a

\begin{tabular}{lcc} 
Study site & Pearson $(r)$ & $P$ \\
\hline Paint & -0.391 & $\mathbf{0 . 0 4 0}$ \\
Long & -0.405 & $\mathbf{0 . 0 2 9}$ \\
Dartmouth & $\mathbf{0 . 5 7 5}$ & $\mathbf{0 . 0 0 6}$ \\
Sturgeon & -0.125 & 0.509 \\
Purdue & -0.515 & $\mathbf{0 . 0 0 4}$ \\
Stortjärn & 0.021 & 0.931 \\
La Croche & -0.031 & 0.899 \\
George & -0.323 & 0.081 \\
Opeongo & -0.435 & $\mathbf{0 . 0 2 6}$ \\
Kraus & -0.487 & $\mathbf{0 . 0 0 5}$ \\
Hertel & -0.082 & 0.74 \\
KBS Reservoir & -0.254 & 0.267 \\
Feresjön & -0.639 & $\mathbf{0 . 0 0 3}$ \\
Erken & 0.051 & 0.506 \\
Convict & -0.851 & $<0.001$ \\
Tavernoles & - & - \\
\hline
\end{tabular}

Cascading effects are indicated by a negative correlation between cladoceran abundance and chlorophyll a. Cladocerans were absent from one study site (Tavernoles). Bold values indicate $P<0.05$.

clearly show that lake food webs are not protected by current $\mathrm{Cl}^{-}$thresholds. We must reassess current thresholds and develop new thresholds where they do not exist to protect our freshwater lakes.

Unlike short-duration (e.g., 48-h $\mathrm{LC}_{50}$ tests), single-species studies, our studies included a community approach that encompasses a greater diversity of zooplankton and species interactions such as predator-prey relationships and competition over a 6- to 7-wk time span. We also leveraged a regression-style design, to better reflect responses of lake food webs to salinization and identify response thresholds. Based on our spatial coverage and environmentally relevant $\mathrm{Cl}^{-}$concentrations, our results suggest that many salt-contaminated lakes with $\mathrm{Cl}^{-}$concentrations near or above thresholds established throughout North America and Europe might have already experienced food web shifts $(30,39)$.

Cladoceran zooplankton were highly sensitive to our $\mathrm{Cl}^{-}$ additions, and $80 \%$ of our study sites were not protected by the lowest $\mathrm{Cl}^{-}$thresholds established by the United States and Canada. In short-term exposures (usually $48 \mathrm{~h}$ ), others have found that species-specific $\mathrm{LC}_{50}$ values of laboratory strains of cladocerans generally exceed $1,200 \mathrm{mg} \mathrm{Cl}^{-} / \mathrm{L}$ (e.g., refs. 27, 28, 40). Experimental work using wild cladocerans collected from lakes with little to no prior salt exposure have found a $>50 \%$ reduction in abundance occurs between 246 and $500 \mathrm{mg} \mathrm{Cl}^{-} / \mathrm{L}$ (e.g., refs. 24, 26, 41). Our estimated $\mathrm{LC}_{50}$ values at $86 \%$ of our sites occurred at or below $230 \mathrm{mg} \mathrm{Cl}^{-} / \mathrm{L}$, and $73 \%$ of those sites occurred at or below $120 \mathrm{mg} \mathrm{Cl}^{-} / \mathrm{L}$. At present, our results are among the lowest $\mathrm{LC}_{50}$ values reported for wild-strain cladoceran communities across lakes that vary in environmental conditions and species composition. These results are consistent with recent work by Arnott et al. (30), who showed that cladocerans can experience negative effects at concentrations of 5 to $40 \mathrm{mg} \mathrm{Cl}-/ \mathrm{L}$, which are well below current government $\mathrm{Cl}^{-}$ thresholds designed to protect aquatic life.

Calanoid copepod zooplankton were also highly susceptible to our experimental $\mathrm{Cl}^{-}$treatments. The US and Canadian $\mathrm{Cl}^{-}$ thresholds did not protect calanoids at $90 \%$ of our study sites. Further, the rapid decline and almost total loss of calanoids at some sites suggests that freshwater calanoids might be much more sensitive to salt pollution than cladocerans. This was also observed in a soft-water, northern boreal oligotrophic lake where saline effluent from mining operations triggered a complete loss of calanoid copepods while some cladocerans and cyclopoid copepods continued to persist over a $10-\mathrm{y}$ time period (42). The highest diversity of calanoid copepods tends to occur in the limnetic zone of freshwater systems (43) where, like cladocerans, they play critically important functional roles in lake food webs as primary consumers and predators and are often a biomass dominant in north temperate lakes (44). Thus, salinization of freshwater lakes could trigger a substantial loss of calanoid diversity and shifts in lake food webs.

Cyclopoid copepods were less impacted by our $\mathrm{Cl}^{-}$treatments compared to cladocerans and calanoid copepods as indicated by the number of sites $(40 \%)$ where the cyclopoid $\mathrm{LC}_{50}$ values were above US and Canadian chronic thresholds. A higher tolerance of cyclopoids among more sites is consistent with previous work showing adult cyclopoids were not as vulnerable to $\mathrm{NaCl}$-induced salinization compared to calanoids and cladocerans $(45,46)$. Even so, the $\mathrm{LC}_{50}$ values for cyclopoids were at or below the US and Canadian thresholds at $33 \%$ of our study sites, and the abundance of cyclopoids at $88 \%$ of sites was lower than the control conditions at those $\mathrm{Cl}^{-}$thresholds, suggesting cyclopoids might still exhibit a high degree of susceptibility to salinization in many freshwater lakes.

Like the other taxa, our data suggest that rotifer zooplankton may not be protected by current $\mathrm{Cl}^{-}$thresholds in many lakes. Rotifer assemblages among $82 \%$ of our study sites had $\mathrm{LC}_{50}$ values at or below the US and Canadian chronic thresholds. There is almost no research examining the impacts of $\mathrm{Cl}^{-}$concentration on rotifers in low-salinity lakes (e.g., naturally $<20$ $\mathrm{mg} \mathrm{Cl}{ }^{-} / \mathrm{L}$ ) and at the lower experimental $\mathrm{Cl}^{-}$concentrations used in our study. Much more research on the impacts of elevated salinity on rotifers has occurred in higher-salinity or estuarine ecosystems, which show a decline in rotifer fecundity with increasing salinity (47). One experimental study on freshwater rotifers found that multiple species exhibit little decline in population size below $910 \mathrm{mg} \mathrm{Cl}^{-} / \mathrm{L}$ (40). Rotifers were much more sensitive in our study, particularly from lakes with low nutrients and ion concentrations, as has been shown with cladocerans $(30,39,48)$. While the mechanism is unclear, freshwater rotifer decline could be due to reduced fecundity with increased salinity (47). Our results indicate that when we consider multiple assemblages of rotifers from a broad spectrum of freshwater lakes (i.e., $<20 \mathrm{mg} \mathrm{Cl}^{-} / \mathrm{L}$ ) that vary in their environmental conditions, rotifers may be more sensitive to salinization effects in low-ion and low-nutrient lakes.

Recent work has shown that water chemistry can affect the response of some zooplankton taxa to salinization. For instance, water hardness and nutrient concentrations can alter the response of cladoceran species to road salt (49). Similarly, other studies show as water hardness (as $\mathrm{CaCO}_{3} / \mathrm{L}$ ) declines, the negative effects of $\mathrm{NaCl}$ increase at lower $\mathrm{Cl}^{-}$concentrations $(30,33)$. This relationship is particularly evident in Canadian Shield lakes where low nutrient concentrations (e.g., $\mathrm{Ca}^{2+}, \mathrm{N}$, and $\mathrm{P}$ ) trigger substantial reductions in cladoceran populations at low $\mathrm{Cl}^{-}$concentrations (30). While the exact mechanism remains unknown, one potential mechanism for the reduction of $\mathrm{Cl}^{-}$toxicity at high water hardness is that higher concentrations of $\mathrm{Ca}^{2+}$ and $\mathrm{Mg}^{2+}$ in harder water can cause cellular junctions to tighten, which reduces passive transport of $\mathrm{Cl}^{-}$into animal tissue (50). Despite a significant range in $\mathrm{Ca}^{2+}$ and other water chemistry variables such as background $\mathrm{Cl}^{-}$concentration, TN, TP, and chlorophyll $a$ among our study sites, these water chemistry variables only explained variation in rotifer responses. The lack of a pattern among other zooplankton taxa might suggest that measured water chemistry variables were not limiting, or it is possible that other unmeasured ions or ion ratios associated with water hardness (e.g., $\mathrm{Mg}^{2+}$ ) were in sufficient supply. Nevertheless, our results illustrate that regulatory thresholds over a gradient of water chemistry among 
freshwater lakes are insufficient to protect zooplankton communities and lake food webs from salinization.

Local genus composition of each group did not explain the variation in $\mathrm{LC}_{50}$ values. However, the response of zooplankton to salinization varies with genotype (51), so intraspecific variation in salt tolerance may explain the variable responses observed among our study sites. Among most of our study sites, one to three of the major taxonomic groups were not protected by the US and Canadian thresholds. However, at $25 \%$ of our study sites we found that all detected zooplankton taxa exhibited $\mathrm{LC}_{50}$ values at or below the thresholds (Croche, Long, Opeongo, and Stortjärn). This could indicate that genotypes from these lakes are the most sensitive to elevated salinity. In other locations (Convict), increases in the abundance of some taxa at low concentrations might indicate salt-tolerant genotypes, although a precipitous decline occurred at the highest $\mathrm{Cl}^{-}$concentrations (52). Given the lack of a relationship with the environmental data for crustacean zooplankton, it is likely that species- and population-level genetic differences due to adaptation to local ecosystem conditions could account for the variable nature of taxa responses among study sites (53). We encourage further investigation into the roles that regional genotypes have on the susceptibility of zooplankton communities to salinization.

Our study suggests that cascading effects from the loss of zooplankton resulting in higher phytoplankton biomass might be common among salinized lakes. While we do not have specieslevel phytoplankton data, it is likely that our high $\mathrm{Cl}^{-}$concentrations also induced shifts in the diversity and abundance of the phytoplankton community (e.g., ref. 54). At one study site, we found a positive relationship between cladoceran abundance and chlorophyll $a$, which could be due to high salinity promoting salttolerant phytoplankton species that could be less palatable for cladocerans. The extent to which phytoplankton communities respond to salinization and the food web implications of such changes remain to be well understood. Ultimately, the nature of salt-induced cascading effects on lake food webs will be complex (55). About half our experimental sites experienced these effects, similar to previous single-site studies $(24,56-58)$. This widespread deterioration of the zooplankton-phytoplankton energy pathway in lake food webs could affect production at higher trophic levels. Previous studies indicate that changes in zooplankton communities can result in poor growth and recruitment of economically important fish species (16). Further, it is unclear what elevated phytoplankton biomass would mean for benthic communities in lakes, but reduced light attenuation or shading effects are possible and could lead to a regime shift due to reduced water clarity $(14,24)$.

Recent research shows evolutionary responses by zooplankton can occur in the form of an increased tolerance to $\mathrm{NaCl}$ (59). It is unclear whether rapid evolution of tolerance is widespread in natural communities and if such a tolerance could buffer zooplankton from the impacts of various sources of salinization such as road salts over the long term. While traits leading to the tolerance can change over short time periods [e.g., a few generations in Daphnia (60)], the durations of our 16 experiments were not long enough to account for evolved responses demonstrated in other studies (59). Nevertheless, while an evolved tolerance to $\mathrm{NaCl}$ and cross-tolerance to other salt types could potentially buffer declines in cladoceran abundance to repeated salt exposure, these evolved responses do not always mitigate the cascading effect we observed here (e.g., ref. 61). Thus, we would not expect evolutionary processes to stabilize the zooplankton-algae energy pathway in freshwater food webs (62).

Conclusions. The $\mathrm{LC}_{50}$ values and magnitude of declines in zooplankton abundance presented here were much larger and occurred at lower concentrations than expected based on published studies $(11,63,64)$. Our results are concerning because substantial changes to community structure, food webs, and ecosystem function are likely to occur well before a $50 \%$ decline in the abundance of major zooplankton taxa. Zooplankton are critical for transferring energy from primary producers to secondary consumers and indirectly to tertiary consumers. A reduction in the biomass of zooplankton can reduce food availability for young fishes and other planktivores, leading to a reduction in growth rates and recruitment (e.g., ref. 16). Many lakes have been salinized to the point where zooplankton in our study experienced declines (65). It is unclear if and to what degree some of the documented and projected ecological effects discussed here have already occurred and how salinization has interacted with other stressors to shape contemporary lake communities.

Our results indicate an immediate need to reassess current governmental thresholds to protect lakes from salinization. In US Midwestern and Northeastern states alone, Dugan et al. (4) estimated that there are 2,000 lakes predicted to have $\mathrm{Cl}^{-}$concentrations $>50 \mathrm{mg} \mathrm{Cl}^{-} / \mathrm{L}$. In the next $50 \mathrm{y}$, many of those lakes will exceed the US threshold of $230 \mathrm{mg} \mathrm{Cl}^{-} / \mathrm{L}$ (3). However, lakes at concentrations of 42 to $90 \mathrm{mg} \mathrm{Cl}^{-} / \mathrm{L}$ have already undergone ecological change (30). Human use of salt sources responsible for freshwater salinization must strike a balance with ecological impacts. For example, road deicing salts reduce vehicle accident rates by 78 to $87 \%$ (66-68), and until ecologically friendly alternatives are available, deicing salts will be needed for the foreseeable future to protect the traveling public. For now, best management practices may dramatically reduce salinization caused by road salt pollution (65). However, there are multiple other sources of salinization to consider, and we must recognize the multitude of chemical mixtures that occur because of the freshwater salinization syndrome occurring globally (69-71). Understanding the interaction among ions in chemical mixtures and how various combinations mediate toxicity is imperative given changing trends in ion composition worldwide (69). We must develop new and lower $\mathrm{Cl}^{-}$ thresholds across the world to protect freshwater communities, which will no doubt be a difficult task. The variability in our experimental results demonstrates that new $\mathrm{Cl}^{-}$thresholds must integrate the susceptibility of ecological communities at the local and regional scales to successfully develop these protective $\mathrm{Cl}^{-}$thresholds.

\section{Materials and Methods}

We conducted 16 experiments in temperate or subarctic ecosystems in North America and Europe (Fig. 4 and SI Appendix, Appendix 1, Table 1.1). The experiments were based on a common protocol and a regression-style experimental design to examine how a wide range of environmentally relevant $\mathrm{Cl}^{-}$ concentrations (from $\mathrm{NaCl}$ that is $>99 \%$ pure; SI Appendix, Appendix 2, Table 2.1) affected zooplankton communities and, in turn, indirectly affected phytoplankton biomass. Each experiment included 20 to 32 mesocosms; of the 16 experiments, we conducted 11 using land-based (tank) mesocosms and 5 using in-lake mesocosms (SI Appendix, Appendix 1, Table 1.1). The lowest concentration was the $\mathrm{Cl}^{-}$found in the source water (ranging from $<2$ to $18 \mathrm{mg} / \mathrm{L}$ ), and we added increasing amounts of $\mathrm{Cl}^{-}$to a highest nominal concentration of $1,500 \mathrm{mg} / \mathrm{L}$ (Fig. 4). We conducted the experiments during 2018, and each lasted for 41 to $51 \mathrm{~d}$ (SI Appendix, Appendix 1, Table 1.1). Further information on the experimental design can be found in SI Appendix, Appendices 1-3 and 5. Supplemental methods text can be found in SI Appendix, Appendix 1.

At the end of each experiment, we concentrated zooplankton by filtering water samples taken from each mesocosm (1.2 to $15 \%$ of the mesocosm volume) using a 50- to 64- $\mu \mathrm{m}$ mesh (SI Appendix, Appendix 5, Tables 5.1 and 5.2). We preserved zooplankton in 70 to $95 \%$ ethanol or Lugol's solution. We subsequently identified and counted zooplankton using stereomicroscopes (10 to $100 \times$ magnification) and standard counting protocols for each laboratory (SI Appendix, Appendix 5.2). We generally identified cladocerans and adult copepods to species and rotifers to genus.

To quantify phytoplankton biomass, at the end of the experiment we sampled 200 to $500 \mathrm{~mL}$ of water from each mesocosm to quantify the concentration of chlorophyll $a$. We then filtered water samples through glass microfiber 


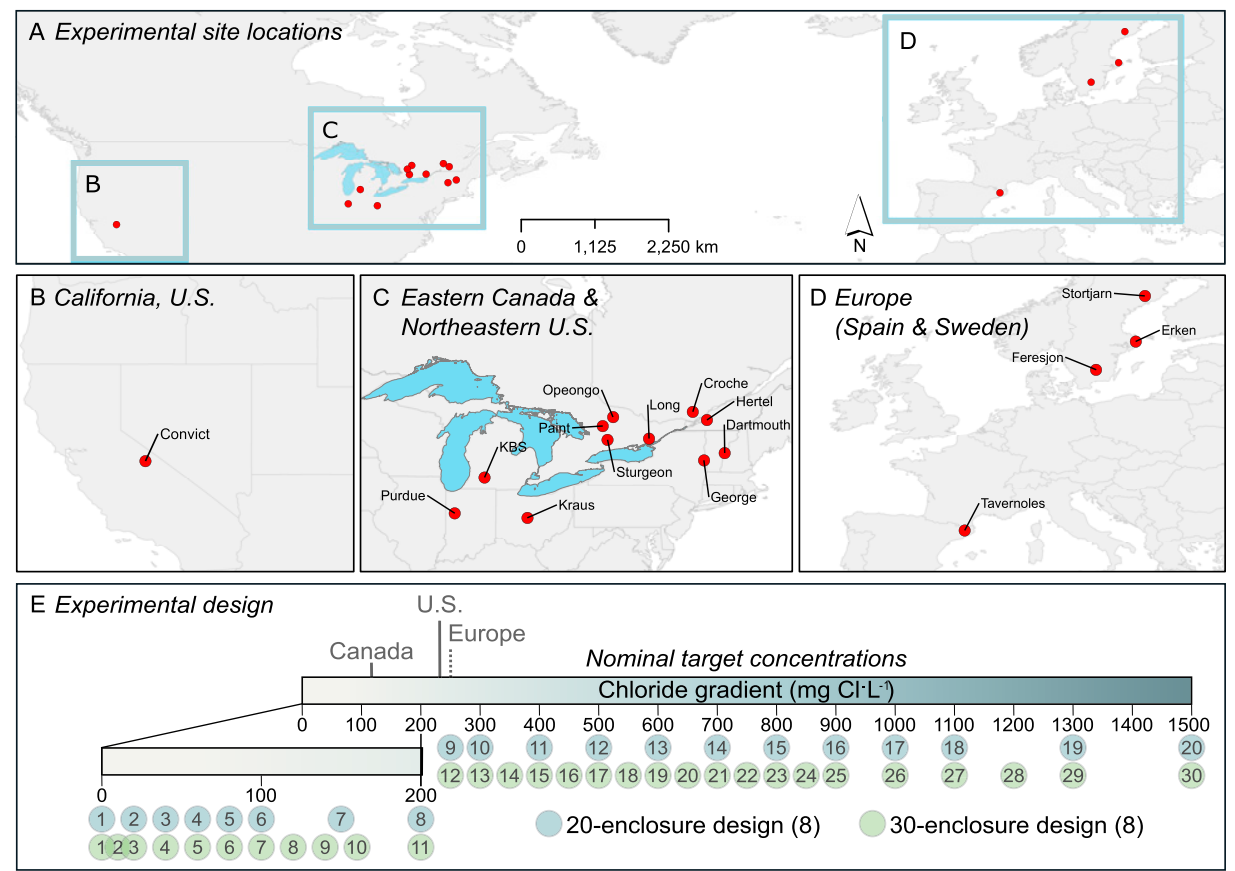

Fig. 4. Map of study sites across North America and Europe where we investigated the impacts of chloride $\left(\mathrm{Cl}^{-}\right)$concentration-a strong indicator of human-induced salinization-on freshwater lake food webs. (A-D) Study site location across North America and Europe. (E) The regression-style design used to test how an environmentally relevant gradient of $\mathrm{Cl}^{-}$concentration affected lake food webs among the study sites. Guidelines for Canada, United States, and Europe are indicated on the gradient.

filters and froze the filters until we conducted chlorophyll $a$ analysis via fluorometry or spectrophotometry (SI Appendix, Appendix 5, Table 5.3).

Statistical Analyses. For all analyses (72), we pooled zooplankton into one of four taxonomic groups: cladocerans, calanoid copepods, cyclopoid copepods, and rotifers (SI Appendix, Appendix 4). We conducted all analyses using R version 4.0.2 ( $\mathrm{R}$ Core Team 2020) using base, $m g c v(73)$, and vegan packages $(74,75)$.

To examine how each group responded to increased salt concentrations, we used GAMs with a generalized cross-validation procedure to provide nonparametric curve fitting, with a $\log _{10}(x+1)$ transformation of the abundance values. We first determined if sites had a similar response to $\mathrm{Cl}^{-}$by fitting a model across all sites for each taxonomic group with the $\log _{10}(x+1)$-transformed abundance as a function of $\mathrm{Cl}^{-}$. We then fit interaction models that incorporated a separate smoothed relationship to $\mathrm{Cl}^{-}$for each of the 16 sites. These models were compared using the Akaike information criterion (AIC); the model with the lowest AIC was chosen as the best candidate model.

Because the best models always included a separate smoothed relationship for each site (SI Appendix, Appendix 4, Tables 4.6 and 4.7), we fit separate models for each site with the $\log _{10}(x+1)$ abundance for each taxonomic group as a function of $\mathrm{Cl}^{-}$. Using these models, for each of the 16 experiments and where possible (see below), we estimated the $\mathrm{Cl}^{-}$concentrations that caused a $50 \%$ reduction in the abundance of each taxonomic group compared to the predicted abundance at the lowest $\mathrm{Cl}^{-}$concentration: this approach is conceptually similar to a traditional $\mathrm{LC}_{50}$ value in a laboratory toxicology experiment (except it incorporates births and mortality), and we refer to it as an $\mathrm{LC}_{50}$ in Results and Discussion. We did not calculate the $\mathrm{LC}_{50}$ for some taxonomic groups when 1) there was no change in abundance with $\mathrm{Cl}^{-}, 2$ ) there was an increase in abundance with $\mathrm{Cl}^{-}$, or 3) zooplankton abundance did not remain below $50 \%$ along the $\mathrm{Cl}^{-}$gradient. In some cases where taxa abundance dramatically decreased at low $\mathrm{Cl}^{-}$concentration, the estimated $\mathrm{LC}_{50}$ was greater than the $\mathrm{Cl}^{-}$concentration for which we detected any individuals of the taxa, making these models unreliable. In these instances, we truncated the high end of the $\mathrm{Cl}^{-}$gradient such that the $\mathrm{Cl}^{-}$range of the tail end of zeros was equal to the gradient of $\mathrm{Cl}^{-}$in which there were individuals present (SI Appendix, Appendix 4, Figs. 4.1-4.4). To compare our results against current water quality guidelines for the protection of aquatic life, we also estimated the percent decline in each taxonomic group at the current threshold values used in Canada (120 mg Cl$-/ \mathrm{L})$ and the United States $\left(230 \mathrm{mg} \mathrm{Cl}^{-} / \mathrm{L}\right)$. We chose these thresholds because they are to the best of our knowledge the lowest known thresholds designed to protect aquatic life.
We assessed if zooplankton sensitivity to $\mathrm{Cl}^{-}$was related to site-level environmental conditions (water chemistry and chlorophyll a) using linear models. Because these variables were highly colinear, we conducted a PCA based on a correlation matrix on $\log _{10}$-transformed variables $\left(\mathrm{Cl}^{-}, \mathrm{Ca}^{2+}, \mathrm{TN}, \mathrm{TP}\right.$, and chlorophyll a). We then used linear models to determine if the $L_{50}$ value for each taxonomic group was related to the individual or combined effects of the first and second PCA axes. Because of the low number of sites, we evaluated the main effects of PC1 and PC2 and did not include their interaction. Statistical support was determined using ANOVA after evaluating model fit by examining residuals versus predicted values, scale-location, and residual versus leverage plots.

We also assessed if zooplankton sensitivity was related to local community composition (SI Appendix, Appendix 6). We first conducted a separate PCA for each taxonomic group (cladocerans, cyclopoids, calanoids, and rotifers) using the abundance of each genus found in control mesocosms. When there were replicates for the control (e.g., Kraus and Dartmouth), we used the average abundance. We then Hellinger-transformed the abundance data and used a correlation matrix for the analyses (76). We then used linear models to determine if the $L C_{50}$ of each taxonomic group was related to the individual or combined effects of the first two PCA axes as described above.

Cascading effects. We examined the relationship between the cladoceran abundance and phytoplankton biomass at the end of the experiment using Pearson correlation coefficients to determine if there was a cascading effect in the experimental food webs. We defined a cascading effect as a significant (i.e., $P \leq 0.05$ ) negative correlation between cladoceran abundance and phytoplankton biomass-i.e., as $\mathrm{Cl}^{-}$concentration increased, the decline in cladoceran abundance would reduce grazing pressure, triggering an increase in phytoplankton biomass along the experimental $\mathrm{Cl}^{-}$gradient. To linearize the data, we $\log _{10}$-transformed chlorophyll a concentration and $\log _{10}(x+1)$-transformed cladoceran abundances.

Data Availability. Excel files, Word files, and PDFs have been deposited and are available in Dataverse (https://doi.org/10.5683/SP3/BIDMCI) (72).

ACKNOWLEDGMENTS. We thank the Canadian Institute for Ecology and Evolution for funding a workshop that facilitated the production of this manuscript Support for the Lake George study site was from the Jefferson Project at Lake George, a collaboration of Rensselaer Polytechnic Institute, IBM, and The FUND for Lake George. W.D.H. was also supported by University of Toledo Faculty Startup Program. Support for the Long Lake study site was provided by a Natural Sciences and Engineering Research Council of Canada (NSERC) Discovery grant and by the Ontario Ministry of Environment, Conservation, and Parks-Best-inScience award for Paint Lake. M.C.-A. was supported by the Serra Hunter 
Programme of the Generalitat de Catalunya. J.A.B. and K.L.C. were funded by the Matariki Foundation awarded to Queen's University and Dartmouth College and the Dartmouth Ecology, Evolution, Environment, and Society Graduate Program. A.M.D., D.K.G., B.E.B., S.J.M., and A.E.K. were funded by NSERC Discovery Grants. S.J.M. acknowledges the support of Harkness Fisheries Research Laboratory for work on Lake Opeongo. N.G. acknowledges support from the Walter and Andrèe de Nottbeck Foundation. C.F.S. was funded by NSF Grant DEB1354063, and J.B.S. was funded by NSF Grant DEB-1457737. M.S. acknowledges funding by DFG (Grant STR 1383/1-1). L.P. has received funding from the Postdoctoral Fellowships Programme Beatriu de Pinós, funded by the Secretary of Universities and Research (Government of Catalonia) and by the Horizon 2020
Programme of Research and Innovation of the European Union under the Marie Skłodowska-Curie Grant Agreement 801370. P.U.-C. was supported from an International Postdoc Grant (2017-06421) from the Swedish Research Council (Vetenskapsrådet). G.A.W. was supported by the Swedish Research Council (Grant 2020-03222). We acknowledge SITES for provisioning of the SITES AquaNet mesocosm facility at sites Asa (Feresjön), Erken, and Svartberget (Stortjärn). SITES receives funding through the Swedish Research Council under Grant 201700635. M.P.H. acknowledges support from G. Fussmann. We thank A. Conway, K. Lange, L. Rightmire, J. Swain, H. Richardson, B. Rathie, and C. Layne for field and laboratory assistance. Last, we want to thank the multiple reviewers whose comments and suggestions helped us improve our manuscript for publication.

${ }^{a}$ Department of Environmental Sciences, The University of Toledo, Toledo, OH 43606; ${ }^{\text {b }}$ Lake Erie Center, The University of Toledo, Oregon, OH 43616; ${ }^{\mathrm{C} B i o l o g y}$ Department, Queen's University, Kingston, ON K7L 3J9, Canada; ${ }^{d}$ Department of Ecology and Evolutionary Biology, University of California, Irvine, CA 92697;

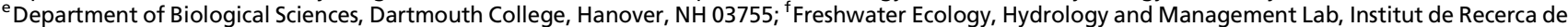
I'Aigua, Universitat de Barcelona, 08007 Barcelona, Spain; ${ }^{9}$ Interuniversity Group in Limnology, Département des Sciences Biologiques, Université du Québec à Montréal, Montréal, QC, H2L 2C4 Canada; ${ }^{h}$ Biology Department, Ohio Wesleyan University, Delaware, OH 43015; 'Department of Biology, Wilfrid Laurier

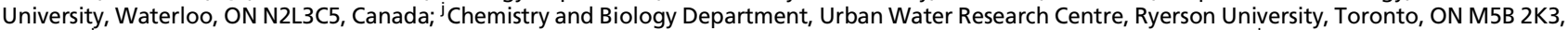
Canada; ${ }^{k}$ Darrin Fresh Water Institute, Department of Biological Sciences, Rensselaer Polytechnic Institute, Troy, NY 12180; 'Dorset Environmental Science Centre, Ontario Ministry of Environment, Conservation and Parks, Dorset, ON POA 1E0, Canada; ${ }^{m}$ Department of Biological Sciences, Purdue University, West Lafayette, IN 47906; ${ }^{n}$ Section of Ecology, Behavior, and Evolution, University of California San Diego, La Jolla, CA 92093; ${ }^{\circ}$ Rui Nabeiro Biodiversity Chair, Mediterranean Institute for Agriculture, Environment and Development, Universidade de Évora, 7004-516 Évora, Portugal; ${ }^{\mathrm{P}}$ Center for the Study of Mediterranean Rivers, University of Vic-Central University of Catalonia, 08500 Manlleu, Spain; ${ }^{9}$ Tvärminne Zoological Station, University of Helsinki, 10900 Hanko, Finland; ' $F$ Faculty of Science, Ontario Tech University, Oshawa, ON, L1G OC5 Canada; ' ${ }^{\circ}$ ' epartment of Biology, McGill University, Montréal, QC, H3A 0G4 Canada; ${ }^{t}$ Centre for Ecology and Evolution in Microbial Model Systems, Department of Biology and Environmental Science, Linnaeus University, SE 39231 Kalmar, Sweden; 'Limnology, Department of Ecology and Genetics, Uppsala University, 75236 Uppsala, Sweden; ${ }^{\mathrm{U}}$ Unit for Field-Based Forest Research, Swedish

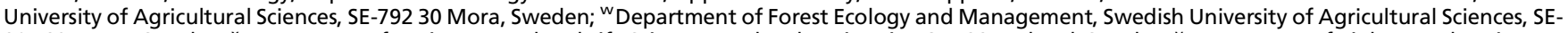
90183 Umea, Sweden; ${ }^{x}$ Department of Environmental and Life Sciences, Karlstads University, 65188 Karlstad, Sweden; ${ }^{y}$ Department of Biology and Environmental Science, Linnaeus University, SE 39231 Kalmar, Sweden; ${ }^{\mathrm{z}}$ Technological Center in Biodiversity, Ecology and Environmental and Food Technology, TECNIO Network, University of Vic-Central University of Catalonia, 08500 Vic, Spain; aa Department of Biology, Montclair State University, Montclair, NJ 07043; ${ }^{\mathrm{b}}$ Department of Biological Sciences, Wayne State University, Detroit, MI 48202; “c Plankton Ecology, Institute for Chemistry and Biology of the Marine Environment, Carl-von-Ossietzky University Oldenburg, 26382 Wilhelmshaven, Germany; and ${ }^{\text {dd }}$ Aquatic Ecology, Department of Biology, Lund University, SE-223 62 Lund, Sweden

1. M. Cañedo-Argüelles et al., Saving freshwater from salts. Science 351, 914-916 (2016).

2. S. S. Kaushal et al., Freshwater salinization syndrome on a continental scale. Proc Natl. Acad. Sci. U.S.A. 115, E574-E583 (2018).

3. H. A. Dugan et al., Salting our freshwater lakes. Proc. Natl. Acad. Sci. U.S.A. 114, 4453-4458 (2017)

4. H. A. Dugan et al., Lakes at risk of chloride contamination. Environ. Sci. Technol. 54 6639-6650 (2020)

5. G. E. Likens, D. C. Buso, Salinization of Mirror Lake by road salt. Water Air Soil Pollut 205, 205-214 (2010)

6. S. S. Kaushal et al., Increased salinization of fresh water in the northeastern United States. Proc. Natl. Acad. Sci. U.S.A. 102, 13517-13520 (2005).

7. J. Thorslund, M. F. P. Bierkens, G. H. P. Oude Essink, E. H. Sutanudjaja, M. T. H. van Vliet, Common irrigation drivers of freshwater salinisation in river basins worldwide. Nat. Commun. 12, 4232 (2021).

8. R. N. Cuthbert et al., Combined impacts of warming and salinisation on trophic interactions and mortality of a specialist ephemeral wetland predator. Freshw. Biol. 64 1584-1592 (2019)

9. T. D. H. Le et al., Predicting current and future background ion concentrations in German surface water under climate change. Philos. Trans. R. Soc. Lond. B Biol. Sci. $\mathbf{3 7 4}$ 20180004 (2018)

10. J. R. Olson, Predicting combined effects of land use and climate change on river and stream salinity. Philos. Trans. R. Soc. Lond. B Biol. Sci. 374, 20180005 (2018)

11. W. D. Hintz, R. A. Relyea, A review of the species, community, and ecosystem impacts of road salt salinisation in fresh waters. Freshw. Biol. 64, 1081-1097 (2019).

12. S. R. Carpenter, J. F. Kitchell, J. R. Hodgson, Cascading trophic interactions and lake productivity. Bioscience 35, 634-639 (1985).

13. M. L. Pace, J. D. Orcutt, The relative importance of protozoans, rotifers, and crustaceans in a freshwater zooplankton community. Limnol. Oceanogr. 26, 822-830 (1981).

14. E. Jeppesen et al., Ecological impacts of global warming and water abstraction on lakes and reservoirs due to changes in water level and related changes in salinity. Hydrobiologia 750, 201-227 (2015)

15. E. Jeppesen et al., Does the impact of nutrients on the biological structure and function of brackish and freshwater lakes differ? Hydrobiologia 275, 15-30 (1994).

16. J. M. Dettmers, M. J. Raffenberg, A. K. Weis, Exploring zooplankton changes in Southern Lake Michigan: Implications for Yellow Perch Recruitment. J. Great Lakes Res. 29, 355-364 (2003).

17. M. Hayashi, G. van der Kamp, D. L. Rudolph, Water and solute transfer between prairie wetland and adjacent uplands, 2. Chloride cycle. J. Hydrol. (Amst.) 207, 56-67 (1998).

18. S. Buvaneshwari et al., Potash fertilizer promotes incipient salinization in groundwater irrigated semi-arid agriculture. Sci. Rep. 10, 3691 (2020).

19. M. Bonte, J. J. G. Zwolsman, Climate change induced salinisation of artificial lakes in the Netherlands and consequences for drinking water production. Water Res. 44 4411-4424 (2010)
20. US Environmental Protection Agency, Ambient Water Quality Criteria for Chlo ride-1988 (US Environmental Protection Agency, 1988).

21. Canadian Council of Ministers of the Environment, "Canadian water quality guidelines for the protection of aquatic life: Chloride" (Environment Canada, Gatineau, QC, Canada, 2011)

22. M. S. Schuler et al., Regulations are needed to protect freshwater ecosystems from salinization. Philos. Trans. R. Soc. Lond. B Biol. Sci. 374, 20180019 (2018).

23. C.-J. Schulz, M. Cañedo-Argüelles, Lost in translation: The German literature on freshwater salinization. Philos. Trans. R. Soc. Lond. B Biol. Sci. 374, 20180007 (2018).

24. W. D. Hintz et al., Salinization triggers a trophic cascade in experimental freshwater communities with varying food-chain length. Ecol. Appl. 27, 833-844 (2017).

25. W. D. Hintz, R. A. Relyea, A salty landscape of fear: Responses of fish and zooplank ton to freshwater salinization and predatory stress. Oecologia 185, 147-156 (2017).

26. C. L. Searle, C. L. Shaw, K. K. Hunsberger, M. Prado, M. A. Duffy, Salinization decreases population densities of the freshwater crustacean, Daphnia dentifera. Hydrobiologia 770, 165-172 (2016).

27. D. R. Mount et al., The acute toxicity of major ion salts to Ceriodaphnia dubia: I. Influ ence of background water chemistry. Environ. Toxicol. Chem. 35, 3039-3057 (2016).

28. A. M. M. Goncalves, B. B. Castro, M. A. Pardal, F. Goncalves, Salinity effects on survival and life history of two freshwater cladocerans (Daphnia magna and Daphnia longispina). Ann. Limnol. Int. J. Limnol. 43, 13-20 (2007).

29. S. R. Corsi, D. J. Graczyk, S. W. Geis, N. L. Booth, K. D. Richards, A fresh look at road salt: Aquatic toxicity and water-quality impacts on local, regional, and national scales. Environ. Sci. Technol. 44, 7376-7382 (2010).

30. S. E. Arnott et al., Road salt impacts freshwater zooplankton at concentrations below current water quality guidelines. Environ. Sci. Technol. 54, 9398-9407 (2020).

31. S. Brucet et al., Species richness of crustacean zooplankton and trophic structure of brackish lagoons in contrasting climate zones: North temperate Denmark and Mediterranean Catalonia (Spain). Ecography 32, 692-702 (2009).

32. T. C. Jensen, S. Meland, A. K. Schartau, B. Walseng, Does road salting confound the recovery of the microcrustacean community in an acidified lake? Sci. Total Environ 478, 36-47 (2014).

33. J. R. F. Elphick, K. D. Bergh, H. C. Bailey, Chronic toxicity of chloride to freshwater species: Effects of hardness and implications for water quality guidelines. Environ. Toxicol. Chem. 30, 239-246 (2011).

34. G. A. Weyhenmeyer et al., Widespread diminishing anthropogenic effects on calcium in freshwaters. Sci. Rep. 9, 10450 (2019).

35. B. J. Kefford et al., Salinized rivers: Degraded systems or new habitats for salttolerant faunas? Biol. Lett. 12, 20151072 (2016).

36. E. T. Borer et al., Finding generality in ecology: A model for globally distributed experiments. Methods Ecol. Evol. 5, 65-73 (2014)

37. J. E. Duffy et al., Biodiversity mediates top-down control in eelgrass ecosystems: A global comparative-experimental approach. Ecol. Lett. 18, 696-705 (2015).

38. P. Urrutia-Cordero et al., SITES AquaNet: An open infrastructure for mesocosm experiments with high frequency sensor monitoring across lakes. Limnol. Oceanogr. Methods 19, 385-400. 
39. R. E. Valleau, A. M. Paterson, J. P. Smol, Effects of road-salt application on Cladocera assemblages in shallow Precambrian Shield lakes in south-central Ontario, Canada. Freshw. Sci. 39, 824-836 (2020).

40. S. S. S. Sarma, S. Nandini, J. Morales-Ventura, I. Delgado-Martinez, L. Gonzalez-Valverde, Effects of $\mathrm{NaCl}$ salinity on the population dynamics of freshwater zooplankton (rotifers and cladocerans). Aquat. Ecol. 40, 349-360 (2006).

41. J. W. Petranka, R. A. Francis, Effects of road salts on seasonal wetlands: Poor prey performance may compromise growth of predatory salamanders. Wetlands 33, 707-715 (2013).

42. G. E. Melville, Changes in the pelagic crustacean zooplankton of high-boreal Island Lake, Saskatchewan, associated with uranium mining. Environ. Monit. Assess. 34, 45-58 (1995).

43. L. A. Błedzki, J. I. Rybak, "Introduction to Copepoda" in Freshwater Crustacean Zooplankton of Europe: Cladocera \& Copepoda (Calanoida, Cyclopoida) Key to Species Identification, with Notes on Ecology, Distribution, Methods and Introduction to Data Analysis (Springer International Publishing, Cham, 2016), pp. 443-444.

44. J. A. Rusak et al., Temporal, spatial, and taxonomic patterns of crustacean zooplankton variability in unmanipulated north-temperate lakes. Limnol. Oceanogr. 47, 613-625 (2002)

45. P. L. Thompson, J. B. Shurin, Regional zooplankton biodiversity provides limited buffering of pond ecosystems against climate change. J. Anim. Ecol. 81, 251-259 (2012).

46. J. S. Sinclair, S. E. Arnott, Local context and connectivity determine the response of zooplankton communities to salt contamination. Freshw. Biol. 63, 1273-1286 (2018).

47. M. R. Miracle, M. Serra, Salinity and Temperature Influence in Rotifer Life History Characteristics (Springer Netherlands, Dordrecht, 1989), pp. 81-102.

48. A. H. Brown, N. D. Yan, Food quantity affects the sensitivity of Daphnia to road salt. Environ. Sci. Technol. 49, 4673-4680 (2015).

49. L. Lind et al., Salty fertile lakes: How salinization and eutrophication alter the structure of freshwater communities. Ecosphere 9, e02383 (2018).

50. D. J. Soucek et al., Influence of water hardness and sulfate on the acute toxicity of chloride to sensitive freshwater invertebrates. Environ. Toxicol. Chem. 30, 930-938 (2011).

51. C. Loureiro et al., Genetic variability in the tolerance of natural populations of Simocephalus vetulus (Muller, 1776) to lethal levels of sodium chloride. Ann. Limnol. Int. J. Limnol. 48, 95-103 (2012).

52. E. R. Moffett, H. K. Baker, C. C. Bonadonna, J. B. Shurin, C. C. Symons, Cascading effects of freshwater salinization on plankton communities in the Sierra Nevada. Limnol. Oceanogr., 10.1002/lol2.10177 (2021).

53. L. De Meester, Local genetic differentiation and adaptation in freshwater zooplank ton populations: Patterns and processes. Ecoscience 3, 385-399 (1996).

54. A. Fazio, I. O'Farrell, Phytoplankton and water quality in a shallow lake: A response to secondary salinization (Argentina). Wetlands 25, 531-541 (2005).

55. R. A. Stein, D. R. DeVries, J. M. Dettmers, Food-web regulation by a planktivore: Exploring the generality of the trophic cascade hypothesis. Can. J. Fish. Aquat. Sci. 52, 2518-2526 (1995).

56. D. K. Jones et al., Investigation of road salts and biotic stressors on freshwater wetland communities. Environ. Pollut. 221, 159-167 (2017).

57. R. J. Van Meter, C. M. Swan, J. Leips, J. W. Snodgrass, Road salt stress induces novel food web structure and interactions. Wetlands 31, 843-851 (2011).
58. R. J. Van Meter, C. M. Swan, C. A. Trossen, Effects of road deicer $(\mathrm{NaCl})$ and amphibian grazers on detritus processing in pond mesocosms. Environ. Toxicol. Chem. 31 2306-2310 (2012)

59. K. D. Coldsnow, B. M. Mattes, W. D. Hintz, R. A. Relyea, Rapid evolution of tolerance to road salt in zooplankton. Environ. Pollut. 222, 367-373 (2017).

60. G. Jeremias et al., Transgenerational inheritance of DNA hypomethylation in Daphnia magna in response to salinity stress. Environ. Sci. Technol. 52, 10114-10123 (2018).

61. W. D. Hintz, D. K. Jones, R. A. Relyea, Evolved tolerance to freshwater salinization in zooplankton: Life-history trade-offs, cross-tolerance and reducing cascading effects. Philos. Trans. R. Soc. Lond. B Biol. Sci. 374, 20180012 (2018).

62. M. Elmarsafy, K. L. Tasky, D. K. Gray, Can zooplankton on the North American Great Plains "keep up" with climate-driven salinity change? Limnol. Oceanogr. 66, 865-877 (2021)

63. A. M. Castillo, D. M. T. Sharpe, C. K. Ghalambor, L. F. De León, Exploring the effects of salinization on trophic diversity in freshwater ecosystems: A quantitative review. Hydrobiologia 807, 1-7 (2018).

64. A. Tiwari, J. W. Rachlin, A review of road salt ecological impacts. Northeastern Naturalist 25, 123-142 (2018)

65. W. D. Hintz, L. Fay, R. A. Relyea, Road salts, human safety, and the rising salinity of our fresh waters. Frontiers in Ecol. \& Environ. 20, 22-30 (2022).

66. J. R. Mullaney, D. L. Lorenz, A. D. Arntson, "Chloride in groundwater and surface water in areas underlain by the glacial aquifer system, northern United States" (Sci. Invest. Rep. 2009-5086, US Geological Survey, 2009).

67. T. Usman, L. Fu, L. F. Miranda-Moreno, Quantifying safety benefit of winter road maintenance: Accident frequency modeling. Accid. Anal. Prev. 42, 1878-1887 (2010).

68. D. A. Kuemmel, R. M. Hanbali, "Accident analysis of ice control operations" (Tech Rep., Department of Civil, Construction, and Environmental Engineering, Marquette University, 1992)

69. S. S. Kaushal et al., Novel 'chemical cocktails' in inland waters are a consequence of the freshwater salinization syndrome. Philos. Trans. R. Soc. Lond. B Biol. Sci. 374 20180017 (2019).

70. S. S. Kaushal et al., Making 'chemical cocktails'-Evolution of urban geochemical processes across the periodic table of elements. Appl. Geochem. 119, 104632 (2020).

71. S. S. Kaushal et al., Freshwater salinization syndrome: From emerging global problem to managing risks. Biogeochemistry 154, 255-292 (2021).

72. S. Arnott et al., Global Salt Experiment. Dataverse. https://dataverse.scholarsportal. info/dataset.xhtml?persistentld=doi:10.5683/SP3/BIDMCI. Deposited 30 November 2021.

73. S. N. Wood, Fast stable restricted maximum likelihood and marginal likelihood estimation of semiparametric generalized linear models. J. R. Stat. Soc. B 73, 3-36 (2011).

74. R Development Core Team, R: A Language and Environment for Statistical Comput ing (Vienna, Austria, 2020). https://www.R-project.org/.

75. J. Oksanen et al., vegan: Community Ecology Package. R package version 2.5-7 (2020). https://CRAN.R-project.org/package=vegan. Accessed 8 February 2022.

76. P. Legendre, E. D. Gallagher, Ecologically meaningful transformations for ordination of species data. Oecologia 129, 271-280 (2001). 